\title{
Covid-19, heat shock proteins, and autoimmune bullous diseases: a potential link deserving further attention
}

\author{
Michael Kasperkiewicz ${ }^{1}$ (D)
}

Received: 23 October 2020 / Revised: 2 November 2020 / Accepted: 9 November 2020 / Published online: 16 November 2020

(C) Cell Stress Society International 2020

\begin{abstract}
A link between Covid-19 and development of autoimmunity has been reported. A possible explanation could be molecular mimicry between SARS-CoV-2 and human proteins. Peptide sharing has been found between antigenic epitopes of this virus and heat shock proteins (Hsp) 60 and 90, both of which are associated with autoimmune diseases including those of the bullous type. In particular, there is evidence for the latter Hsp acting as a pathophysiological factor and treatment target in autoimmune blistering dermatoses. Considering multimodal anti-inflammatory mechanisms of action of anti-Hsp90 treatment and drug repositioning results, it may be hypothesized that Hsp90 inhibition could also be a treatment option for cytokine stormmediated acute respiratory distress syndrome in Covid-19 patients. Hence, although Covid-19-induced autoimmune bullous diseases have not been described in the literature so far, the potential relationship between Covid-19, Hsp, and these autoimmune disorders deserves further attention with respect to both pathophysiology and treatment.
\end{abstract}

Keywords Autoimmunity $\cdot$ Covid- $19 \cdot$ Heat shock proteins $\cdot$ SARS-CoV-2

A link between Covid-19 and the development of autoimmunity has been reported (Ehrenfeld et al. 2020), although the pathophysiological processes induced by the SARS-CoV-2 infection remain widely unknown. One possible explanation could be molecular mimicry between the virus and human proteins, where immune responses raised against SARSCoV-2 cross-react with human proteins that share peptide sequences with the virus. In fact, peptide sharing has been found between SARS-CoV-2 antigenic epitopes and different human proteins including chaperones (Ehrenfeld et al. 2020; Marino Gammazza et al. 2020).

In a recent study by Lucchese and Flöel (2020), for example, sequence analysis of human proteins linked to immunemediated neuropathies revealed molecular mimicry between SARS-CoV-2 and human heat shock proteins (Hsp) 60 and 90, which are associated with Guillain-Barré syndrome and other autoimmune diseases, suggesting a possible pathogenic mechanism of neuropathy after SARS-CoV-2 infection. In this context, it is worth mentioning that we have previously

Michael Kasperkiewicz

Michael.Kasperkiewicz@med.usc.edu

1 Department of Dermatology, Keck School of Medicine, University of Southern California, Los Angeles, CA, USA provided evidence for a role of autoantibodies to Hsp60 and Hsp90, which correlated with disease-specific autoantibodies, in patients with the autoimmune bullous disease dermatitis herpetiformis (Kasperkiewicz et al. 2014). In addition, our previous comprehensive studies using experimental models and assays of epidermolysis bullosa acquisita and bullous pemphigoid revealed that Hsp90 represents a crucial pathophysiological factor and treatment target in autoimmune blistering dermatoses (Tukaj et al. 2015).

It has been suggested that the progression of Covid-19 to a systemic disease (i.e., widespread microvascular damage, diffuse thrombosis, disseminated intravascular coagulation) could depend on the Hsp-related molecular mimicry autoimmune phenomena (Cappello et al. 2020). Of note, past studies showed that the coagulation cascade is activated in bullous pemphigoid and correlates with the severity of blistering (Cugno et al. 2019). This, in turn, raises the speculative question whether some immunosuppressive therapies could be regarded as a double-edged sword in patients with autoimmune bullous diseases, protecting them not only from blister formation but also from mutually influential severe complications of Covid-19. Intriguingly, considering the multimodal anti-inflammatory mechanisms of action of anti-Hsp90 treatment and an online pre-published drug repositioning study (Sultan et al. 2020; Tukaj et al. 2015), it may be hypothesized 
that Hsp90 inhibition could also be a potential option of treatment for cytokine storm-mediated acute respiratory distress syndrome in Covid-19 patients.

Therefore, although Covid-19-induced autoimmune bullous diseases have not been described in the literature so far (Kasperkiewicz 2020), the potential relationship between Covid-19, Hsp, and autoimmune blistering disorders deserves further attention with respect to both pathophysiology and treatment.

\section{Compliance with ethical standards}

Conflict of interest none.

\section{References}

Cappello F, Marino Gammazza A, Dieli F, de Macario EC, Macario AJL (2020) Does SARS-CoV-2 trigger stress-induced autoimmunity by molecular mimicry? A hypothesis. J Clin Med 9:2038

Cugno M, Borghi A, Garcovich S, Marzano AV (2019) Coagulation and skin autoimmunity. Front Immunol 10:1407

Ehrenfeld M, Tincani A, Andreoli L, Cattalini M, Greenbaum A, Kanduc D, Alijotas-Reig J, Zinserling V, Semenova N, Amital H, Shoenfeld Y (2020) Covid-19 and autoimmunity. Autoimmun Rev 19:102597
Kasperkiewicz M, Tukaj S, Gembicki AJ, Silló P, Görög A, Zillikens D, Kárpáti S (2014) Evidence for a role of autoantibodies to heat shock protein 60,70 , and 90 in patients with dermatitis herpetiformis. Cell Stress Chaperones 19:837-843

Kasperkiewicz M (2020) COVID-19 outbreak and autoimmune bullous diseases: a systematic review of published cases. J Am Acad Dermatol. https://doi.org/10.1016/j.jaad.2020.08.012

Lucchese G, Flöel A (2020) SARS-CoV-2 and Guillain-Barré syndrome: molecular mimicry with human heat shock proteins as potential pathogenic mechanism. Cell Stress Chaperones 25:731-735

Marino Gammazza A, Légaré S, Lo Bosco G, Fucarino A, Angileri F, Conway de Macario E, Macario AJ, Cappello F (2020) Human molecular chaperones share with SARS-CoV-2 antigenic epitopes potentially capable of eliciting autoimmunity against endothelial cells: possible role of molecular mimicry in COVID-19. Cell Stress Chaperones 25:737-741

Sultan I, Howard S, Tbakhi A (2020) Drug repositioning suggests a role for the heat shock protein 90 inhibitor geldanamycin in treating COVID-19 infection. Res Square. https://doi.org/10.21203/rs.3.rs$18714 / \mathrm{v} 1$

Tukaj S, Zillikens D, Kasperkiewicz M (2015) Heat shock protein 90: a pathophysiological factor and novel treatment target in autoimmune bullous skin diseases. Exp Dermatol 24:567-571

Publisher's note Springer Nature remains neutral with regard to jurisdictional claims in published maps and institutional affiliations. 